Article

\title{
Coating of a Sand-Blasted and Acid-Etched Implant Surface with a pH-Buffering Agent after Vacuum-UV Photofunctionalization
}

\author{
Chang-Joo Park ${ }^{1,+}$, Jae Hyung Lim ${ }^{2,+}{ }^{\text {, Marco Tallarico }}{ }^{3}{ }^{\circledR}$, Kyung-Gyun Hwang ${ }^{1}$, Hyook Choi ${ }^{1}$, \\ Gyu-Jang Cho ${ }^{1}$, Chang Kim ${ }^{1}$, Il-Seok Jang ${ }^{4}$, Ju-Dong Song ${ }^{4}$, Amy M. Kwon ${ }^{5}$, Sang Ho Jeon ${ }^{6}$ \\ and Hyun-Kyung Park ${ }^{7, *}$ \\ 1 Division of Oral and Maxillofacial Surgery, Department of Dentistry, College of Medicine, \\ Hanyang University, Seoul 04763, Korea; fastchang@hanyang.ac.kr (C.-J.P.); hkg@hanyang.ac.kr (K.-G.H.); \\ chlgur3@nate.com (H.C.); chogu@hanmail.net (G.-J.C.); himychang0@naver.com (C.K.) \\ 2 Division of Oral and Maxillofacial Surgery, Department of Dentistry, Korea University Ansan Hospital, \\ Ansan 15355, Korea; surgidenta@gmail.com \\ 3 Department of Periodontology and Implantology, University of Sassari, 7100 Sassari, Italy; \\ me@studiomarcotallarico.it \\ 4 Osstem R\&D Center, Seoul 07789, Korea; microart@osstem.com (I.-S.J.); jud@osstem.com (J.-D.S.) \\ 5 Biostatistic Core, Medicine-Engineering-Bio (MEB) Global Development Research Centre, \\ Hanyang University, Seoul 04763, Korea; amykwon@hanyang.ac.kr \\ 6 Department of Oral and Maxillofacial Surgery, Korea University Anam Hospital, Seoul 02841, Korea; \\ junsang@korea.ac.kr \\ 7 Division of Neonatology, Department of Paediatrics, College of Medicine, Hanyang University, \\ Seoul 04763, Korea \\ * Correspondence: neopark@hanyang.ac.kr; Tel.: +82-2-2290-8391 \\ $\dagger$ These two authors contributed equally to this work.
}

Received: 24 September 2020; Accepted: 28 October 2020; Published: 28 October 2020

\begin{abstract}
Ultraviolet (UV) photofunctionalization can reset the biological aging of titanium after the preparation and storage of dental implants by transforming hydrophobic titanium surfaces into superhydrophilic surfaces. Blood clot formation around the implant can initialize and promote the healing process at the bone-implant interface. The aim of this study is to evaluate and compare the capabilities of surface wettability and blood clotting of implants with a conventional sand-blasted and acid-etched surface (SA), a sand-blasted and acid-etched surface with vacuum-UV treatment $(\mathrm{SA}+\mathrm{VUV})$, and a sand-blasted and acid-etched surface coated with a $\mathrm{pH}$-buffering agent after vacuum-UV treatment $(S A+V U V+B S)$. Static and dynamic tests for surface wettability and blood clotting were performed in vitro for SA + VUV and SA + VUV + BS $(n=5)$, while hemostasis resulting from blood clotting was evaluated in vivo for SA, SA +VUV, and SA + VUV + BS $(n=4)$. A Kruskal-Wallis test showed statistically significant differences $(p<0.05)$ in all tests, with the exception of in vitro test of static blood clotting. VUV treatment is therefore effective at making an SA surface superhydrophilic as an alternative to routine UV-C radiation. The addition of a pH-buffering agent to SA + VUV also improved surface wettability and blood clotting, which are crucial for successful osseointegration.
\end{abstract}

Keywords: blood clotting; dental implants; hydrophilicity; titanium; ultraviolet rays

\section{Introduction}

Titanium has been widely used for dental and orthopedic restoration and reconstruction due to its biocompatibility, resistance to corrosion, and mechanical properties. Titanium oxidizes easily, 
forming a thin (1-5 nm), stable, and passive layer that is self-limiting and protects the surface of the metal from further oxidation [1]. This titanium dioxide $\left(\mathrm{TiO}_{2}\right)$ surface layer is considered to be responsible for its effective biological performance due to the transfer of calcium and phosphorus ions from the bone matrix within the $\mathrm{TiO}_{2}$ layer [2]. However, significant reductions in osseointegration and other biological capabilities of titanium occur over time as surface carbon increases because of an unavoidable deposition of carbon from the atmosphere on the $\mathrm{TiO}_{2}$ layer in a form of hydrocarbon [3]. This phenomenon is defined as the biological aging of titanium, and the ability of titanium surfaces to attract proteins and osteogenic cells decreases in a time-dependent manner [4]. Another notable change in titanium surfaces with time is the disappearance of hydrophilicity. Immediately after processing, titanium surfaces exhibit a contact angle of water of 0 or less than 5 degrees, and such surfaces are called superhydrophilic [4-7]. This feature gradually attenuates and becomes hydrophobic in 2 and 4 weeks, with a contact angle of greater than 40 and 60 degrees, respectively.

Surface treatment is used to modify dental implant surface topography and energy, resulting in improved wettability, increased cell proliferation and growth, and accelerated osseointegration $[1,8,9]$. Surface treatment can be achieved by an additive or subtractive technique [9]. The subtractive technique either removes or roughens a layer of core material, as typified by a sand-blasted and acid-etched (SA) surface. In the addictive technique, other materials or chemical agents are added superficially to the surface of the titanium through coating, such as titanium plasma spraying, hydroxyapatite coating, calcium phosphate coating, and other biomimetic coating. Drilling prior to implant placement causes bone tissue to undergo trauma similar to a fracture. The site becomes relatively hypoxic, and the extracellular $\mathrm{pH}$ becomes acidic. In such conditions, bone marrow stromal cells exhibit reduced alkaline phosphatase (ALP) activity and collagen synthesis, both of which are important in bone formation and osseointegration [10]. Glycolysis and DNA synthesis of osteoblasts are also found to be affected by acidic conditions [11]. Platelet aggregation, which is a critical step in blood clot formation or thrombogenesis, is also reduced by extracellular acidosis, as mediated by the calcium ion entry pathway [12]. Formation of a sufficient blood clot offers a direct and stable link at the bone-to-implant interface and plays an important role in thrombogenic responses and osseointegration [13]. Moreover, a relationship was found between various implant surface and the extent of the fibrin clot [14].

In our previous study, a novel SA surface coated with a $\mathrm{pH}$-buffering agent after vacuum-UV (VUV) treatment was introduced $[15,16]$. This surface was closely associated with greater affinity for proteins, cells, and platelets, which promoted rapid and stable blood clotting, thrombogenesis, and osseointegration. The purpose of the present study was to evaluate and compare the surface wettability and blood clotting abilities of various implant surfaces, including a conventional SA surface (SA), an SA surface with VUV treatment (SA + VUV), and an SA surface coated with a pH-buffering agent after VUV treatment (SA + VUV + BS), by in vitro and in vivo analyses.

\section{Materials and Methods}

\subsection{Preparation of Implant Fixtures}

Implant fixtures of commercially pure titanium (grade IV) were prepared as SA, SA + VUV (TS III SA, Osstem, Seoul, Korea), and SA + VUV + BS (TS III SOI, Osstem) for use in this study. As shown in Figure 1a,b, the surface roughness of the implant fixtures were measured to be $2.5 \pm 0.5 \mu \mathrm{m}$ of $R_{a}$ value [15], and VUV treatment for photofunctionalization was achieved by exposing an implant fixture to low-pressure mercury-arc lamps emitting UV-C and VUV in UV ozone cleaner for $1 \mathrm{~h}$. Coating the implant surface with a $\mathrm{pH}$-buffering agent, comprising both of positively and negatively charged ionic groups, with 7.31 of pKa value at $37^{\circ} \mathrm{C}[15,16]$, was supplemented for better superhydrophilicity (Figure 1c). 


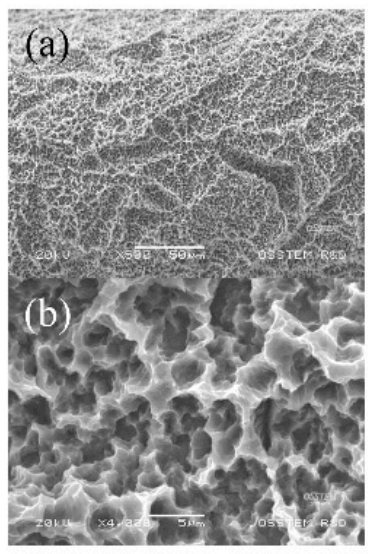

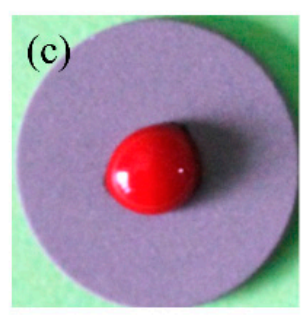

SA

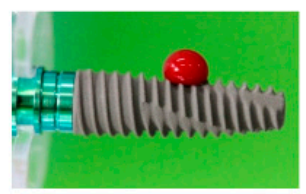

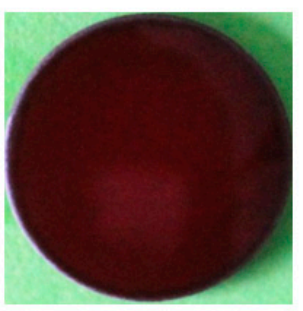

$\mathrm{SA}+\mathrm{VUV}+\mathrm{BS}$

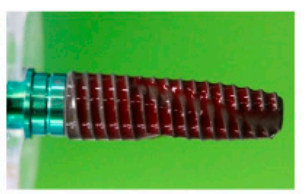

Figure 1. Morphologic observation of a sand-blasted and acid-etched (SA) surface by scanning electron microscope (SEM) at $\times 500$ (a) and $\times 4000$ magnification (b); (c) Comparison of contact angles of defibrinated sheep blood on titanium discs and implant fixtures, respectively. SA, a conventional SA surface; SA + VUV + BS, an SA surface coated with a pH-buffering agent after vacuum-UV treatment.

\subsection{In Vitro Tests}

\subsubsection{Static Surface Wettability}

Heparinized sheep blood was filled in a dish $3.5 \mathrm{~cm}$ in diameter to a depth of 2 to $3 \mathrm{~cm}$. Implant fixtures of SA + VUV and SA + VUV + BS ( $n=5$, respectively) were immersed in blood up to the uppermost discontinuation of apical threads, and the time to reach the top of the implant fixture was recorded to calculate the wetting velocity. The time was not counted from the apex of the implant fixture, because the presence of discontinuation of apical threads caused blood absorption to stop abruptly.

\subsubsection{Dynamic Surface Wettability}

To simulate the clinical situations of implant fixture installation, holes were made in a transparent acrylic plate to secure visibility, according to the manufacturer's drilling protocol for hard bone density using a 122 Taper Kit (Osstem). A $130 \mu \mathrm{M}$ sample of defibrinated sheep blood was placed into each hole of the acrylic plate, and the implant fixtures of SA + VUV and SA + VUV + BS ( $n=5$, respectively) were dipped into the hole by a push-pull gauge (MX-500N, Imada Co., Tokyo, Japan) at a speed of $50 \mathrm{~mm} / \mathrm{min}$, and the times when the blood reached up to the $2 \mathrm{~mm}$ and $4 \mathrm{~mm}$ points of the central axis of the fixture above the horizontal plate, respectively, were recorded (Figure 2).

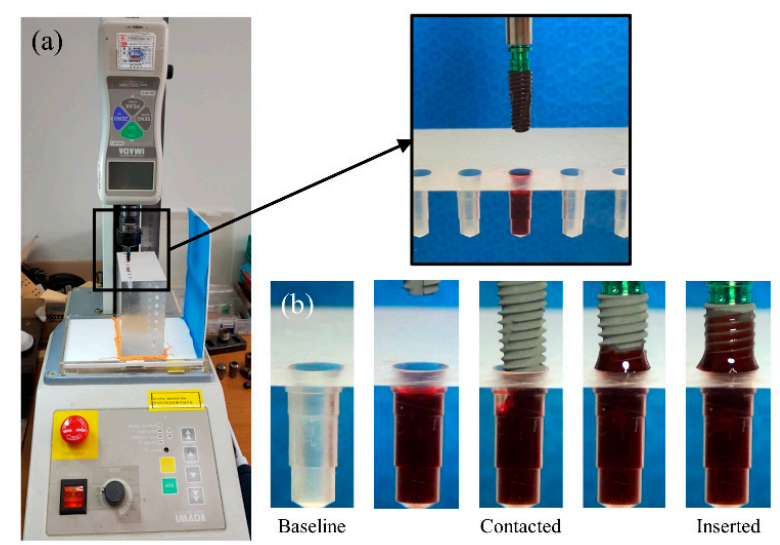

Figure 2. In vitro test of dynamic surface wettability: (a) a transparent acrylic plate with implant holes and the implant fixture in a push-pull gauge; (b) baseline, contact of the implant fixture with the blood, and whole insertion of implant fixture into the hole. 


\subsubsection{Static Blood Clotting}

The implant fixtures of SA + VUV and SA + VUV + BS, $11.5 \mathrm{~mm}$ long with $4.5 \mathrm{~mm}$ diameter ( $n=5$, respectively), were dipped up to their ends in a dish $3.5 \mathrm{~cm}$ in diameter filled with $3 \mathrm{~mL}$ of non-heparinized sheep blood. The weight $(\mathrm{g})$ of the blood clot around the implant fixture was measured at $5 \mathrm{~min}, 7.5 \mathrm{~min}, 10 \mathrm{~min}$, and $12.5 \mathrm{~min}$, respectively.

\subsubsection{Dynamic Blood Clotting}

This model for active blood clotting was designed to simulate continuous blood supply by capillaries. The SA + VUV and SA + VUV + BS implant fixtures, which were $10 \mathrm{~mm}$ long with a $4.0 \mathrm{~mm}$ diameter $(n=5)$, were inserted with $5 \mathrm{~N}$ cm of pre-set insertion torque into a modified Eppendorf tube, which was connected to a syringe pump infusing the sheep blood, mixed with $1 \mathrm{IU} / \mathrm{mL}$ heparin, on the bottom at $37^{\circ} \mathrm{C}$. After $30 \mathrm{~min}$ of blood supply at an infusion rate of $0.05 \mathrm{~mL} / \mathrm{min}$, the time (min) until blood ceased dropping by blood clot formation around the implant fixture and the volume $(\mathrm{mL})$ of blood, which was collected in the underlying $15 \mathrm{~mL}$ tube below the Eppendorf tube, were measured.

\subsection{In Vivo Test}

A beagle dog mandible model was used. All procedures were conducted with the approval of the Ethics Committee of Animal Experimentation of the Institutional Animal Care and Use Committee (CRONEX-IACUC 20191002; Cronex, Hwasung, Korea) according to the guidelines of Animal Research: Reporting in Vivo Experiments (ARRIVE).

Four female beagles 18 months of age were subjected to bilateral extraction of their mandibular premolars and the first molar under general anesthesia. The anesthetic protocol for all surgical procedures included a $1 \mathrm{~mL}$ intramuscular injection with a $15 \mathrm{mg} / \mathrm{kg}$ dose of tiletamine/zolazepam (Zoletil 50, Virbac, Seoul, Korea) and $5 \mathrm{mg} / \mathrm{kg}$ xylazine (Rompun, Bayer Korea, Seoul, Korea). After local anesthesia, a full-thickness mucoperiosteal flap was raised adjacent to the mandibular premolars and molars (Figure 3). Teeth were hemisected under copious irrigation with a small fissure bur. Extractions were performed with elevators and forceps. Flaps were closed with single interrupted sutures. Postoperative care protocol included antibiotics and pain control. During this interval, all dogs were maintained on a soft diet and water ad libitum.

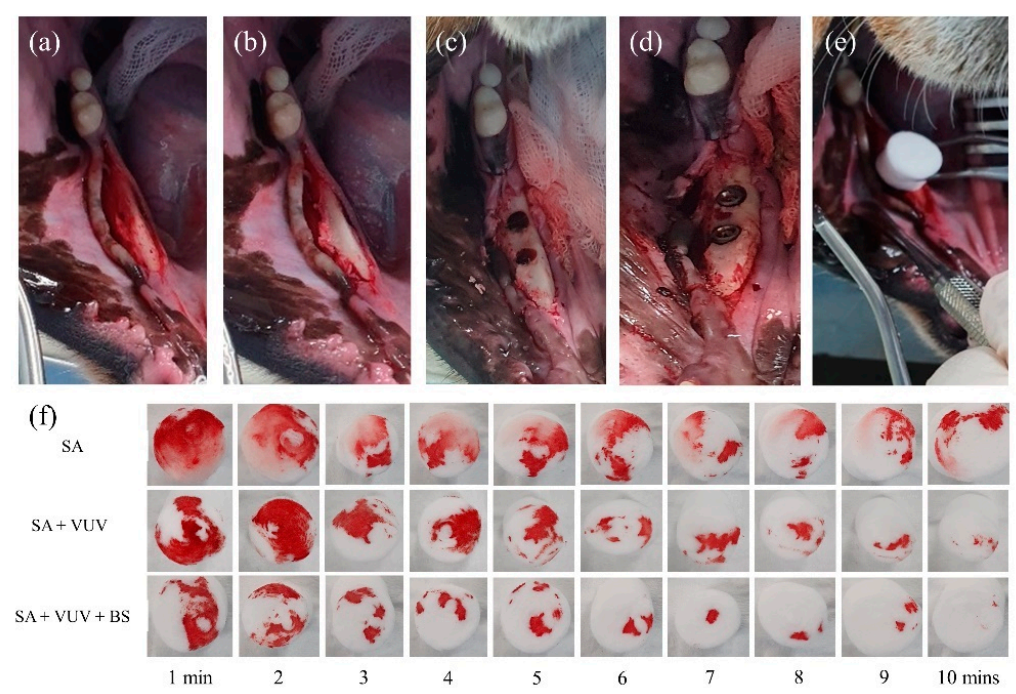

Figure 3. In vivo test of blood clotting: (a) incision and flap reflection; (b) alveolar ridge flattening; (c) preparation of implant holes; (d) implant fixture placement; (e) cotton pellet application for bleeding absorption; (f) pattern of cotton pellets according to time. SA, a conventional SA surface; SA + VUV, an SA surface with vacuum-UV treatment; SA + VUV + BS, an SA surface coated with a pH-buffering agent after vacuum-UV treatment. 
Three months after the extractions, surgical placement of dental implants was performed in the healed extraction sites under sterile conditions. After local anesthesia, a full-thickness flap was elevated to expose the alveolar ridge, and the irregular alveolar crestal was flattened. Sequential drillings were performed for consecutive implant sites, which were larger than the implant fixture, using a guide drill, $2.2 \mathrm{~mm}$ twist drill, $3.0 \mathrm{~mm}$ taper drill, $4.0 \mathrm{~mm}$ taper drill, and $6.0 \mathrm{~mm}$ ultra-taper drill. A total of 12 implant fixtures of SA, SA + VUV, and SA + VUV + BS, $8.5 \mathrm{~mm}$ long with a $3.5 \mathrm{~mm}$ diameter, were placed bilaterally with $35 \mathrm{~N}$ cm of pre-set insertion torque. Whole bleeding from the gap between the hole and implant fixture was socked in a cotton pellet until $10 \mathrm{~min}$ after implant placement, and the weight $(\mathrm{g})$ of the cotton pellet was measured every minute to evaluate the potential of the blood clotting of the implant fixtures. All experimental animals were sacrificed after the surgery by an intravenous overdose of potassium chloride.

\subsection{Statistical Analysis}

Due to a small sample size, we performed a Kruskal-Wallis test, which is a nonparametric comparison of the difference of the means without a normality assumption, to examine the differences between SA + VUV and S + VUV + BS in vitro and among SA, SA + VUV and SA + VUV + BS in vivo, with a statistical significance of $p<0.05$ at $\alpha=0.05$. All statistical analyses were performed using SAS, version 9.4 (SAS Inc., Cary, NC, USA).

\section{Results}

\subsection{In Vitro Tests}

\subsubsection{Static Surface Wettability}

The lengths of time before the blood reached the top of the implant fixture were $43.3 \pm 8.3 \mathrm{~min}$ and $3.8 \pm 0.3 \mathrm{~min}$ in SA + VUV and SA + VUV + BS, respectively, and a statistically significant difference $(p<0.05)$ between the two was evident (Figure 4a).

(a)

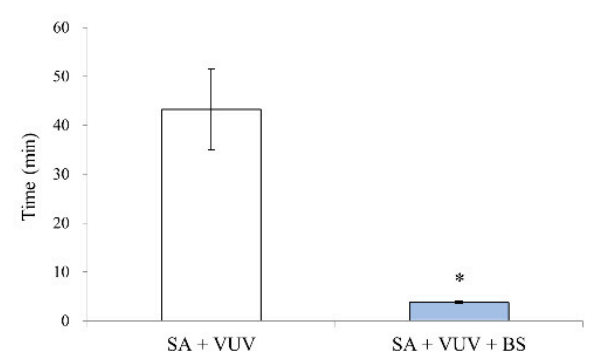

(b)

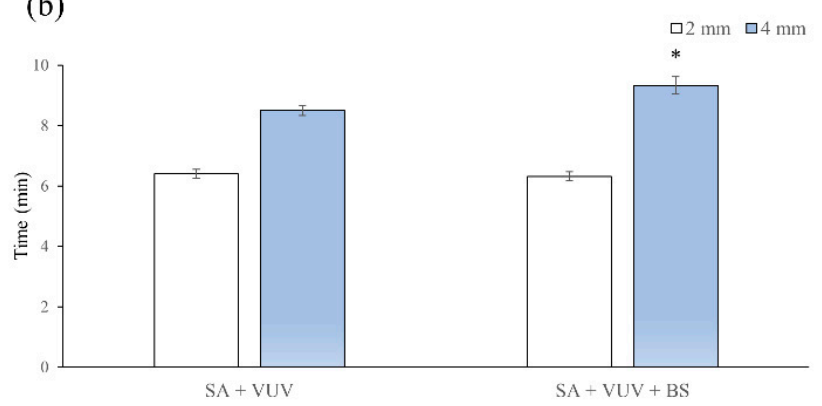

Figure 4. In vitro test of static and dynamic surface wettability: (a) time (min) to reach the top of the implant fixture; (b) time ( $\mathrm{min}$ ) to reach $2 \mathrm{~mm}$ and $4 \mathrm{~mm}$ above the horizontal plate, respectively. SA + VUV, an SA surface with vacuum-UV treatment; SA + VUV + BS, an SA surface coated with a $\mathrm{pH}$-buffering agent after vacuum-UV treatment. Mean $\pm \mathrm{SD},{ }^{*} p<0.05$ by Kruskal-Wallis test.

\subsubsection{Dynamic Surface Wettability}

The lengths of time before the blood reached $2 \mathrm{~mm}$ above the horizontal plate were $6.4 \pm 0.1 \mathrm{~min}$ and $6.3 \pm 0.2 \mathrm{~min}$, and for $4 \mathrm{~mm}$ above the horizontal plate, they were $8.5 \pm 0.2 \mathrm{~min}$ and $9.3 \pm 0.3 \mathrm{~min}$ in SA + VUV and SA + VUV + BS, respectively. A statistically significant difference $(p<0.05)$ between $\mathrm{SA}+\mathrm{VUV}$ and SA + VUV + BS was only found for the time before the blood reached $4 \mathrm{~mm}$ above the horizontal plate (Figure $4 \mathrm{~b}$ ). 


\subsubsection{Static Blood Clotting}

In SA + VUV, the weights of the blood clot formed around the implant fixture, which were measured at $5 \mathrm{~min}, 7.5 \mathrm{~min}, 10 \mathrm{~min}$, and $12.5 \mathrm{~min}$ after immersing the implant fixture in the blood, were $0.04 \pm 0.01 \mathrm{~g}, 0.09 \pm 0.03 \mathrm{~g}, 0.23 \pm 0.06 \mathrm{~g}$, and $0.39 \pm 0.16 \mathrm{~g}$, respectively. In SA + VUV + BS, the weights were $0.07 \pm 0.03 \mathrm{~g}, 0.12 \pm 0.02 \mathrm{~g}, 0.39 \pm 0.20 \mathrm{~g}$, and $0.61 \pm 0.18 \mathrm{~g}$, respectively, and no statistically significant differences were measured between SA + VUV and SA + VUV + BS at any time $(p>0.05)$.

\subsubsection{Dynamic Blood Clotting}

The times for complete hemostasis were $19.0 \pm 0.4 \mathrm{~min}$ and $8.1 \pm 1.2 \mathrm{~min}$ in SA + VUV and SA + VUV + BS, respectively, and there was a statistically significant difference between SA + VUV and $\mathrm{SA}+\mathrm{VUV}+\mathrm{BS}(p<0.01$, Figure $5 \mathrm{a})$. In addition, the volumes of the blood collected in the underlying tube were $8.27 \pm 0.36 \mathrm{~mL}$ and $3.64 \pm 0.99 \mathrm{~mL}$ in SA + VUV and SA + VUV + BS, respectively, with a statistically significant difference $(p<0.01$, Figure $5 b)$ evident between SA + VUV and SA + VUV + BS.

(a)

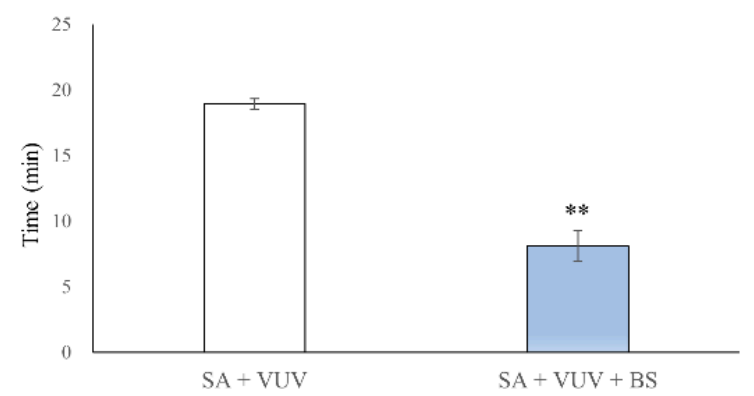

(b)

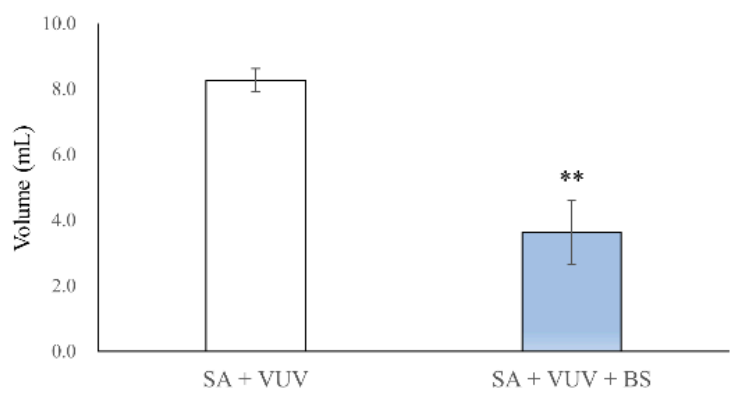

Figure 5. In vitro test of dynamic blood clotting: (a) time (min) until complete hemostasis; (b) volume $(\mathrm{mL})$ of the blood collected in the underlying tube. SA + VUV, an SA surface with vacuum-UV treatment; SA + VUV + BS, an SA surface coated with a $\mathrm{pH}$-buffering agent after vacuum-UV treatment. Mean $\pm \mathrm{SD},{ }^{* *} p<0.01$ by Kruskal-Wallis test.

\subsection{In Vivo Test}

Among SA, SA + VUV, and SA + VUV + BS, there were statistically significant differences in the weights of the whole blood absorbed in the cotton pellet measured at $5 \mathrm{~min}, 6 \mathrm{~min}$, and $7 \mathrm{~min}(p<0.01$, Figure 6). Summary statistics of this study are shown in Table 1.

Table 1. Summary Statistics of this Study.

\begin{tabular}{ccccccc}
\hline Tests & Categories & Groups & N & $\chi^{2}$ & DF & $p$ Value \\
\hline In vitro & Static surface wettability & SA + VUV vs. SA + VUV + BS & 5 & 3.8571 & 1 & $0.0495^{*}$ \\
& Dynamic surface wettability & SA + VUV vs. SA + VUV + BS & 5 & - & - & - \\
& $2 \mathrm{~mm}$ & - & - & 0.4839 & 1 & 0.4867 \\
& $4 \mathrm{~min}$ & - & - & 4.5000 & 1 & $0.0339^{*}$ \\
& Static blood clotting & SA + VUV vs. SA + VUV + BS & 5 & - & - & - \\
& $5 \mathrm{~min}$ & - & - & 2.3333 & 1 & 0.1266 \\
& $7.5 \mathrm{~min}$ & - & - & 1.1905 & 1 & 0.2752 \\
& $10 \mathrm{~min}$ & - & - & 2.3333 & 1 & 0.1266 \\
& $12.5 \mathrm{~min}$ & - & - & 1.1905 & 1 & 0.2752 \\
& Dynamic blood clotting & SA + VUV vs. SA + VUV + BS & 5 & - & - & - \\
In vivo & Time & - & - & 12.9630 & 2 & $0.0015^{* *}$ \\
& Volume & - & - & 12.5448 & 2 & $0.0019^{* *}$ \\
\hline
\end{tabular}

DF: degrees of freedom, N: number of samples, SA: a conventional SA surface; SA + VUV: an SA surface with vacuum-UV treatment; SA + VUV + BS: an SA surface coated with a pH-buffering agent after vacuum-UV treatment. ${ }^{*} p<0.05$ and ${ }^{* *} p<0.01$ by Kruskal-Wallis test. 


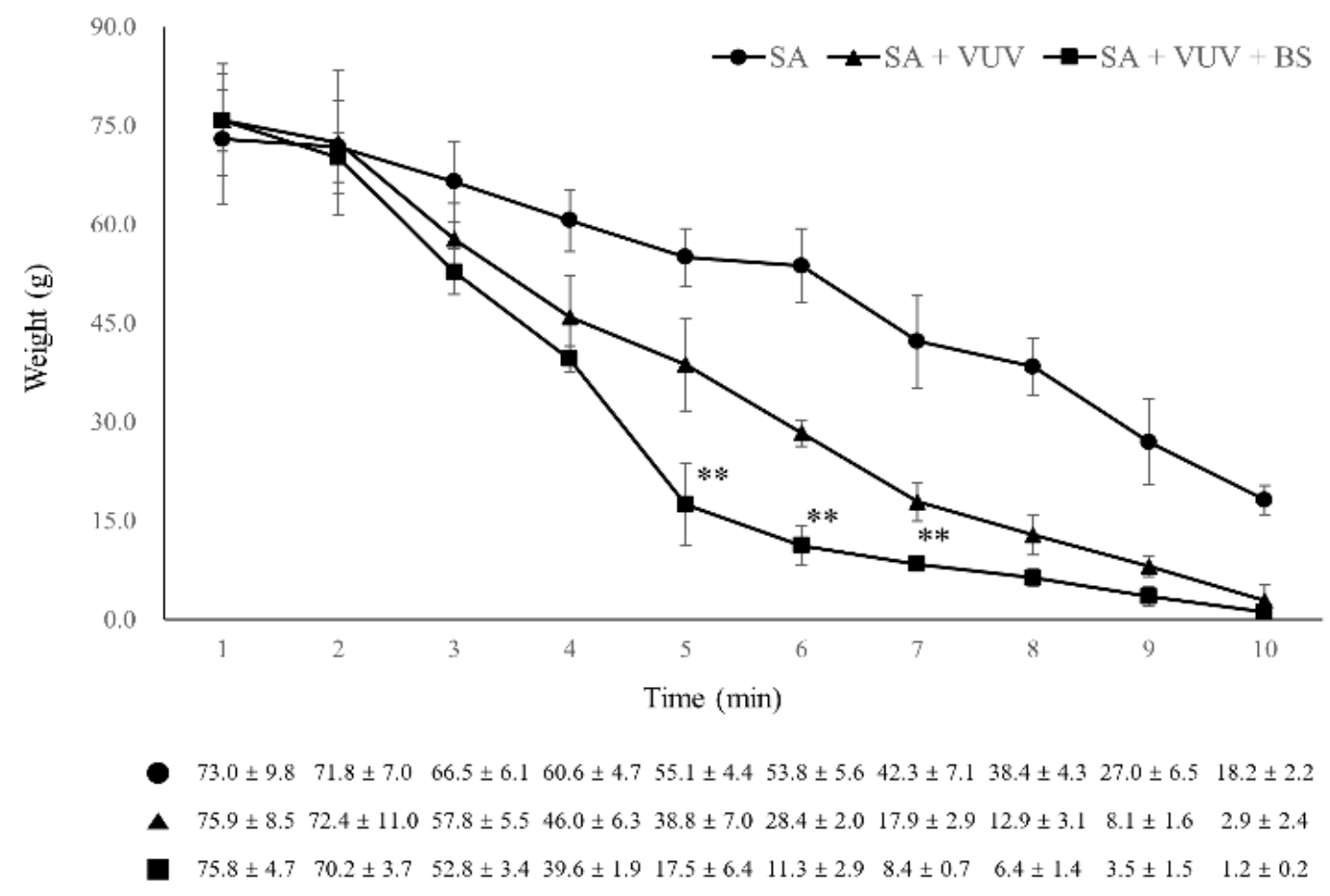

Figure 6. In vivo test of blood clotting. Weight $(\mathrm{g})$ of the whole blood absorbed in the cotton pellet measured from each implant site according to time. SA, a conventional SA surface; SA + VUV, an SA surface with vacuum-UV treatment; SA + VUV + BS, an SA surface coated with a pH-buffering agent after vacuum-UV treatment. Mean $\pm \mathrm{SD},{ }^{* *} p<0.01$ by Kruskal-Wallis test.

\section{Discussion}

UV photofunctionalization, a method of modifying titanium surfaces after UV treatment that includes altering the physicochemical properties and enhancing biocompatibilities, has been proposed to reset the biological aging of titanium [7]. After treatment with UV radiation, the $\mathrm{TiO}_{2}$ layer of a titanium surface incorporated with hydrocarbons became remarkably hydrophilic or superhydrophilic. The amount of surface carbon is known to vary depending on the age of the surface and reportedly can increase to approximately $60 \%$ to $70 \%$ of surface atomic components. UV treatment cleans such carbon-contaminated titanium surfaces, reducing the carbon percentage to less than $20 \%$ and concurrently increasing the level of osseointegration [7]. In the UV spectrum, both UV-A and UV-C convert biologically aged titanium surfaces from hydrophobic to superhydrophilic, but only UV-C $(200-280 \mathrm{~nm})$ is known to effectively reduce surface carbon to a level equivalent to a new surface and enhance bioactivity [17]. UV-C is capable of removing hydrocarbon from a $\mathrm{TiO}_{2}$ layer of titanium by direct photodecomposition, which is more effective than photocatalysis by UV-A [18]. In our study, all implant fixtures were photofunctionalized by UV-C and VUV (100-200 nm), and the radical removal of hydrocarbon from $\mathrm{TiO}_{2}$ layer of titanium could provide more superhydrophilicity $[15,19]$. VUV is rapidly absorbed by water in the atmosphere and is therefore capable of generating various reactive oxygen species by breaking hydrogen bonds in water molecules via hydrolysis [19]. VUV-initiated hydrolysis is an efficient method of obtaining hydroxide or hydroxyl groups on a $\mathrm{TiO}_{2}$ layer that provides persistent superhydrophilicity $[20,21]$. Since VUV treatment tends to generate more ozone in the atmosphere and hydroxyl radicals in water [19], it should be strictly limited in only laboratory or factory, not clinical, settings.

To accelerate bone healing and improve bone anchorage to an implant, the bone/implant interface can be improved topographically and biochemically by incorporating inorganic phases, such as calcium phosphate, and organic molecules, such as proteins, enzymes or peptides, on or into a $\mathrm{TiO}_{2}$ layer [22-25]. Nanostructured implant surfaces, which have an extensive surface area, high surface free energy, and wettability, seem capable of modifying the host tissue response [9]. SA implant surfaces 
have demonstrated predictable clinical results and are regarded as standard implant surface [10,26-29]. The superhydrophilicity of SA + VUV + BS, which was previously found on the flat surface of disks [15], was confirmed in our test of static surface wettability. As the ability to attract blood near to the top of the implant fixture (approximately $4 \mathrm{~mm}$ above the horizontal plate in our study) is what most clinicians ultimately prefer to check in a clinical setting, we added a new dynamic test of surface wettability to compare the wetting velocities of SA + VUV and SA + VUV + BS in more detail. Since SA is a dry surface that has not been in contact with any liquid, the surface wettability of SA + VUV + BS might be significantly superior to that of SA solely by the effect of the pH-buffering agent of SA + VUV + BS itself. However, given that implant fixtures are placed with dry surfaces or without any additional hydration in real clinical situations, we chose a naïve SA, rather than an SA hydrated in solution, as a control [30]. A more hydrophilic surface was previously found to be closely related to superior and faster osseointegration [30,31]. Furthermore, surface wettability is known to alter the biological responses of implant surfaces with respect to the adhesion of proteins and other molecules, as well as cell interactions [32].

As blood clot formation signals the beginning of the healing process, the interaction between an implant and blood is considered important for the successful osseointegration of titanium implants after implantation [33]. Blood clot formation on rough titanium surfaces can induce cell recruitment and stimulate wound healing [34], and it has been revealed that both preosteoblasts and osteoblasts can attach to an implant surface covered by platelets and fibrin, where they differentiate under the stimulation of osteogenic factors and cytokines released from the peri-implant blood clot $[35,36]$. The formation of blood clots on the implant with various implant surfaces is believed to be a crucial factor in effective fibrin retention and may critically affect bone healing and osseointegration by influencing macromolecule transport, cell behavior, and contact/distant osteogenesis [34]. In a test of static blood clotting, the SA + VUV + BS showed superior blood absorption around the implant fixtures compared with SA + VUV, but not to statistically significant degree. This indicates that an SA surface photofunctionalized with VUV has at least an equal ability in blood clotting. We designed new experiments to confirm the blood clotting by hemostasis of continuous capillary bleedings to simulate real clinical situations as accurately as possible. In a test of in vitro dynamic blood clotting, the clots formed significantly faster, and the total volume of blood collecting through the gap between holes and implant fixture to hemostasis was significantly less in SA + VUV + BS than in SA + VUV. An in vivo test also showed a significant difference in the total weight of bleeding between the overprepared hole and an implant fixture among SA, SA + VUV, and SA + VUV + BS. This suggests that SA + VUV + BS can induce faster blood clot formation around the implant surface, leading to more effective interaction of the bone-to-implant interface for osseointegration. In a clinical respect, these features of SA + VUV + BS are important in visualizing the surgical site and simultaneous guided bone regeneration, which is frequently indicated for the adequate quantity and quality of peri-implant tissues for more aesthetic and functional results [37], because rapid blood clotting is closely associated with the stabilization of grafting material and the barrier membrane. Finally, SA + VUV could be an alternative to SA + VUV + BS to SA with respect to the potential for blood clot formation on implant surfaces.

During implant drilling in the bone, which produces a weakly acidic condition, a $\mathrm{pH}$ buffer may help keep the $\mathrm{pH}$ constant [38]. As a coating material, the $\mathrm{pH}$-buffering agent appears to control the release of the inflammatory mediators [9] and enhance the conditions for osteoblast activity [15] by keeping the $\mathrm{pH}$ constant or at least preventing significant changes. The activity of platelets in blood clotting and both the activity of osteoblasts and the level of ALP for bone making are also inhibited by extracellular acidosis [11]. SA + VUV + BS could maximize the activity of platelets, thrombogenesis, the activity of osteoblasts, and the level of ALP in a bone-to-implant interface through a pH-buffering effect. Further studies will be necessary to investigate SA + VUV + BS with respect to its safety and effectiveness in clinical settings. Randomized controlled trials should also be followed to confirm its feasibility in various clinical conditions, such as implant placement immediately after tooth extraction or with simultaneous bone augmentation. 
Author Contributions: Conceptualization, C.-J.P. and H.-K.P.; methodology, I.-S.J. and J.-D.S.; software, A.M.K. and H.-K.P.; validation, C.-J.P., K.-G.H., and H.-K.P.; formal analysis, J.H.L., M.T., K.-G.H., and A.M.K.; investigation, I.-S.J. and J.-D.S.; resources, M.T., K.-G.H., and J.H.L.; data curation, H.C., G.-J.C., and C.K.; writing-original draft preparation, C.-J.P. and J.H.L.; writing—review and editing, M.T., H.C., and S.H.J.; visualization, G.-J.C., C.K., and S.H.J.; supervision, H.-K.P. All authors have read and agreed to the published version of the manuscript.

Funding: This research was supported by the research fund of Medicine-Engineering-Bio (MEB) Global Center for Developmental Disorders, Hanyang University (HY-2020-000-0000-2809).

Conflicts of Interest: The authors declare no conflict of interest.

\section{References}

1. Özcan, M.; Hämmerle, C. Titanium as a reconstruction and implant material in dentistry: Advantages and pitfalls. Materials 2012, 5, 1528-1545. [CrossRef]

2. Ehrenfest, D.M.D.; Coelho, P.G.; Kang, B.S.; Sul, Y.T.; Albrektsson, T. Classification of osseointegrated implant surfaces: Materials, chemistry and topography. Trends Biotechnol. 2010, 28, 198-206. [CrossRef]

3. Milošev, I.; Metikoš-Huković, M.; Strehblow, H.H. Passive film on orthopedic TiAlV alloy formed in physiological solution investigated by X-ray photoelectron spectroscopy. Biomaterials 2000, 21, $2103-2113$. [CrossRef]

4. Lee, J.H.; Ogawa, T. The biological aging of titanium implants. Implant Dent. 2012, 21, 415-421. [CrossRef]

5. Hori, N.; Att, W.; Ueno, T.; Sato, N.; Yamada, M.; Saruwatari, L.; Suzuki, T.; Ogawa, T. Age-dependent degradation of the protein adsorption capacity of titanium. J. Dent. Res. 2009, 88, 663-667. [CrossRef]

6. Hori, N.; Ueno, T.; Suzuki, T.; Iwasa, F.; Yamada, M.; Att, W.; Okada, S.; Ohno, A.; Aita, H.; Kimoto, K. Ultraviolet light treatment for the restoration of age-related degradation of titanium bioactivity. Int. J. Oral Maxillofac. Implant. 2010, 25, 49-62.

7. Ogawa, T. Ultraviolet photofunctionalization of titanium implants. Int. J. Oral Maxillofac. Implant. 2014, 29, e95-e102. [CrossRef] [PubMed]

8. Rosales-Leal, J.; Rodríguez-Valverde, M.; Mazzaglia, G.; Ramón-Torregrosa, P.; Díaz-Rodríguez, L.; García-Martínez, O.; Vallecillo-Capilla, M.; Ruiz, C.; Cabrerizo-Vílchez, M. Effect of roughness, wettability and morphology of engineered titanium surfaces on osteoblast-like cell adhesion. Colloids Surf. Physicochem. Eng. Aspects 2010, 365, 222-229. [CrossRef]

9. Cicciù, M.; Fiorillo, L.; Herford, A.S.; Crimi, S.; Bianchi, A.; D'Amico, C.; Laino, L.; Cervino, G. Bioactive titanium surfaces: Interactions of eukaryotic and prokaryotic cells of nano devices applied to dental practice. Biomedicines 2019, 7, 12. [CrossRef]

10. Li, D.; Ferguson, S.J.; Beutler, T.; Cochran, D.L.; Sittig, C.; Hirt, H.P.; Buser, D. Biomechanical comparison of the sandblasted and acid-etched and the machined and acid-etched titanium surface for dental implants. J. Biomed. Mater. Res. 2002, 60, 325-332. [CrossRef]

11. Kaysinger, K.K.; Ramp, W.K. Extracellular $\mathrm{pH}$ modulates the activity of cultured human osteoblasts. J. Cell. Biochem. 1998, 68, 83-89. [CrossRef]

12. Marumo, M.; Suehiro, A.; Kakishita, E.; Groschner, K.; Wakabayashi, I. Extracellular pH affects platelet aggregation associated with modulation of store-operated $\mathrm{Ca}^{2+}$ entry. Thromb. Res. 2001, 104, 353-360. [CrossRef]

13. Hong, J.; Kurt, S.; Thor, A. A hydrophilic dental implant surface exhibit thrombogenic properties in vitro. Clin. Implant Dent. Relat. Res. 2013, 15, 105-112. [CrossRef]

14. Di Iorio, D.; Traini, T.; Degidi, M.; Caputi, S.; Neugebauer, J.; Piattelli, A. Quantitative evaluation of the fibrin clot extension on different implant surfaces: An in vitro study. J. Biomed. Mater. Res. 2005, 74, 636-642. [CrossRef]

15. Pae, H.C.; Kim, S.K.; Park, J.Y.; Song, Y.W.; Cha, J.K.; Paik, J.W.; Choi, S.H. Bioactive characteristics of an implant surface coated with a $\mathrm{pH}$ buffering agent: An in vitro study. J. Periodontal Implant. Sci. 2019, 49, 366-381. [CrossRef]

16. Cho, Y.S.; Hwang, K.G.; Jun, S.H.; Tallarico, M.; Kwon, A.M.; Park, C.J. Radiologic comparative analysis between saline and platelet-rich fibrin filling after hydraulic transcrestal sinus lifting without adjunctive bone graft: A randomized controlled trial. Clin. Oral Implant. Res. 2020. [CrossRef] [PubMed] 
17. Att, W.; Hori, N.; Iwasa, F.; Yamada, M.; Ueno, T.; Ogawa, T. The effect of UV-photofunctionalization on the time-related bioactivity of titanium and chromium-cobalt alloys. Biomaterials 2009, 30, 4268-4276. [CrossRef]

18. Shie, J.L.; Lee, C.H.; Chiou, C.S.; Chang, C.T.; Chang, C.C.; Chang, C.Y. Photodegradation kinetics of formaldehyde using light sources of UVA, UVC and UVLED in the presence of composed silver titanium oxide photocatalyst. J. Hazard. Mater. 2008, 155, 164-172. [CrossRef]

19. McGivney, E.; Carlsson, M.; Gustafsson, J.P.; Gorokhova, E. Effects of UV-C and Vacuum-UV TiO ${ }_{2}$ advanced oxidation processes on the acute mortality of microalgae. Photochem. Photobiol. 2015, 91, 1142-1149. [CrossRef]

20. Westall, J.; Hohl, H. A comparison of electrostatic models for the oxide solution interface. Adv. Colloid Interface Sci. 1980, 12, 265-294. [CrossRef]

21. Tang, L.; Thevenot, P.; Hu, W. Surface chemistry influences implant biocompatibility. Curr. Top. Med. Chem. 2008, 8, 270-280. [CrossRef]

22. Coelho, P.G.; Granjeiro, J.M.; Romanos, G.E.; Suzuki, M.; Silva, N.R.; Cardaropoli, G.; Thompson, V.P.; Lemons, J.E. Basic research methods and current trends of dental implant surfaces. J. Biomed. Mater. Res. 2009, 88, 579-596. [CrossRef]

23. Puleo, D.; Nanci, A. Understanding and controlling the bone-implant interface. Biomaterials 1999, 20, $2311-2321$. [CrossRef]

24. Morra, M.; Cassinelli, C.; Cascardo, G.; Mazzucco, L.; Borzini, P.; Fini, M.; Giavaresi, G.; Giardino, R. Collagen I-coated titanium surfaces: Mesenchymal cell adhesion and in vivo evaluation in trabecular bone implants. J. Biomed. Mater. Res. 2006, 78, 449-458. [CrossRef] [PubMed]

25. Morra, M. Biochemical modification of titanium surfaces: Peptides and ECM proteins. Eur. Cell. Mater. 2006, 12, 15. [CrossRef]

26. Makowiecki, A.; Hadzik, J.; Błaszczyszyn, A.; Gedrange, T.; Dominiak, M. An evaluation of superhydrophilic surfaces of dental implants-a systematic review and meta-analysis. BMC Oral Health 2019, 19, 79. [CrossRef]

27. Khandelwal, N.; Oates, T.W.; Vargas, A.; Alexander, P.P.; Schoolfield, J.D.; Alex McMahan, C. Conventional SLA and chemically modified SLA implants in patients with poorly controlled type 2 diabetes mellitus-A randomized controlled trial. Clin. Oral Implant. Res. 2013, 24, 13-19. [CrossRef]

28. Kokovic, V.; Jung, R.; Feloutzis, A.; Todorovic, V.S.; Jurisic, M.; Hämmerle, C.H. Immediate vs. early loading of SLA implants in the posterior mandible: 5-year results of randomized controlled clinical trial. Clin. Oral Implant. Res. 2014, 25, e114-e119. [CrossRef]

29. Cesaretti, G.; Botticelli, D.; Renzi, A.; Rossi, M.; Rossi, R.; Lang, N.P. Radiographic evaluation of immediately loaded implants supporting 2-3 units fixed bridges in the posterior maxilla: A 3-year follow-up prospective randomized controlled multicenter clinical study. Clin. Oral Implant. Res. 2016, 27, 399-405. [CrossRef]

30. Buser, D.; Broggini, N.; Wieland, M.; Schenk, R.; Denzer, A.; Cochran, D.; Hoffmann, B.; Lussi, A.; Steinemann, S. Enhanced bone apposition to a chemically modified SLA titanium surface. J. Dent. Res. 2004, 83, 529-533. [CrossRef]

31. Lang, N.P.; Salvi, G.E.; Huynh-Ba, G.; Ivanovski, S.; Donos, N.; Bosshardt, D.D. Early osseointegration to hydrophilic and hydrophobic implant surfaces in humans. Clin. Oral Implant. Res. 2011, 22, 349-356. [CrossRef] [PubMed]

32. Gittens, R.A.; Scheideler, L.; Rupp, F.; Hyzy, S.L.; Geis-Gerstorfer, J.; Schwartz, Z.; Boyan, B.D. A review on the wettability of dental implant surfaces II: Biological and clinical aspects. Acta Biomater. 2014, 10, 2907-2918. [CrossRef]

33. Shiu, H.T.; Goss, B.; Lutton, C.; Crawford, R.; Xiao, Y. Formation of blood clot on biomaterial implants influences bone healing. Tissue Eng. Part B Rev. 2014, 20, 697-712. [CrossRef]

34. Yang, J.; Zhou, Y.; Wei, F.; Xiao, Y. Blood clot formed on rough titanium surface induces early cell recruitment. Clin. Oral Implant. Res. 2016, 27, 1031-1038. [CrossRef]

35. Gassling, V.; Hedderich, J.; Açil, Y.; Purcz, N.; Wiltfang, J.; Douglas, T. Comparison of platelet rich fibrin and collagen as osteoblast-seeded scaffolds for bone tissue engineering applications. Clin. Oral Implant. Res. 2013, 24, 320-328. [CrossRef] 
36. Naik, B.; Karunakar, P.; Jayadev, M.; Marshal, V.R. Role of platelet rich fibrin in wound healing: A critical review. J. Conserv. Dent. 2013, 16, 284. [CrossRef]

37. Beretta, M.; Poli, P.P.; Pieriboni, S.; Tansella, S.; Manfredini, M.; Cicciù, M.; Maiorana, C. Peri-implant soft tissue conditioning by means of customized healing abutment: A randomized controlled clinical trial. Materials 2019, 12, 3041. [CrossRef]

38. Kohn, D.H.; Sarmadi, M.; Helman, J.I.; Krebsbach, P.H. Effects of pH on human bone marrow stromal cells in vitro: Implications for tissue engineering of bone. J. Biomed. Mater. Res. 2002, 60, 292-299. [CrossRef]

Publisher's Note: MDPI stays neutral with regard to jurisdictional claims in published maps and institutional affiliations.

(C) 2020 by the authors. Licensee MDPI, Basel, Switzerland. This article is an open access article distributed under the terms and conditions of the Creative Commons Attribution (CC BY) license (http://creativecommons.org/licenses/by/4.0/). 